\title{
Baby sign but not spontaneous gesture predicts later vocabulary in children with Down Syndrome
}

\author{
Şeyda Özçalı;şkan, Lauren B. Adamson, Nevena Dimitrova, Jhonelle Bailey, and Lauren \\ Schmuck \\ Georgia State University
}

\begin{abstract}
Early spontaneous gesture, specifically deictic gesture, predicts subsequent vocabulary development in typically developing (TD) children. Here we ask whether deictic gesture plays a similar role in predicting later vocabulary size in children with DS, who have been shown to have difficulties in speech production, but strengths in spontaneous gesture and baby sign use. We compared the gestures and baby signs produced by 23 children with DS $\left(\mathrm{M}_{\mathrm{age}}=2 ; 6\right)$ and $23 \mathrm{TD}$ children $\left(M_{\mathrm{age}}=1 ; 6\right)$, in relation to their expressive spoken vocabulary size one year later. Children with DS showed significant deficits in gesture production, particularly for deictic gestures, but strengths in baby sign production, compared to their typically developing peers. More importantly, it was the baby signs produced by children with DS, but not deictic gestures, that predicted their spoken vocabulary size one year later. Our results further highlight the important role baby signs can play in language development in children with developmental disorders.
\end{abstract}

\section{Introduction}

Children use their hands to communicate about objects before they produce verbal labels for these objects. For example, they point at a cat or produce the sign 'cat' by moving their fingers in the shape of a cat's whiskers under their nose before they say the word "cat" several months later. These early gestures and signs ${ }^{1}$, in turn, have effects on spoken language development of typically developing (TD) children, predicting the content and size of their subsequent vocabularies (Goodwyn, Acredolo, \& Brown, 2000; Iverson \& GoldinMeadow, 2005; Rowe, Özçalı;şkan, \& Goldin-Meadow, 2008). Compared to TD children, children with Down Syndrome (DS) show extensive delays in producing their first words; they also use fewer words compared to TD children (e.g., Tager-Flusberg, 2007; TagerFlusberg et al., 1990). At the same time, children with DS show particular strengths in the nonverbal modality - producing gestures and signs at rates comparable to mental-age matched TD children (Stefanini, Caselli, \& Volterra, 2007). The question we ask here is whether the deficits that are commonly observed in the spoken vocabulary development of children with DS are related to their gesture or sign production. Existing evidence suggests

Address for correspondence: Şeyda Özçalı;şkan, Georgia State University, Department of Psychology, PO Box 5010, Atlanta, GA 30302-5010, Phone: (404) 413-6282, Fax: (404) 413-6207, ; Email: seyda@gsu.edu

${ }_{1}$ Even though the term baby sign has been largely popularized with the publication of the book, Baby Sign (Acredolo \& Goodwyn,

1996), the use of similar sign systems can be traced back to early 1970s, with the use of Makaton-a sign system that was largely based on British Sign Language and created for children and adults with communication difficulties (Walker, 1977). 
two alternative possibilities. One possibility is that the use of baby signs at the early ages will be a good predictor of later vocabulary size in children with DS (Goodwyn et al., 2000), who rely on signs more extensively because of the difficulties they encounter in speech production (Abrahamsen, Cavallo, \& McCluer, 1985). The early signs frequently become the first words children with DS will eventually produce (Kouri, 1989), suggesting a tight positive relation between early signs and later spoken vocabulary. An alternative, however, is that early spontaneous gesture, particularly the variability observed in the production of deictic gestures, will be a strong predictor of later spoken vocabulary in children with DS-a pattern that has been shown to be true for both TD children and children with autism spectrum disorders (ASD; Özçalı;şkan, Adamson \& Dimitrova, 2015).

\section{Role of gesture and baby sign in the language development of typically developing children}

Gesture plays an important role in the spoken language development of TD children. Children both indicate and request objects with gesture before they use words to convey similar communicative intentions (Bates, Benigni, Bretherton, Camaioni, \& Volterra, 1979; Iverson, Capirci, \& Caselli, 1994, Iverson, Capirci, Longobardi, \& Caselli, 1999 ; Özçalı;şkan \& Goldin-Meadow, 2005a, 2005b). They use deictic gestures to refer to objects (e.g., point at a ball), conventional gestures to express culturally shared meanings with prescribed gesture forms (e.g., shaking the head to mean 'no', shrugging shoulders to convey 'I don't know'), and iconic gestures to convey information about the characteristic actions or attributes associated with objects (e.g., flapping arms to convey flying, opening arms widelyspaced apart to convey the big size of a bird; Özçalı;şkan \& Goldin-Meadow, 2011). These early gestures, most notably deictic gestures, have both immediate and long-term effects on children's spoken language development. The earlier a child indicates a particular object in gesture, the earlier the same child will produce a spoken label for that object (Iverson \& Goldin-Meadow, 2005). Similarly, the greater number of meanings a child can convey in gesture at age $1 ; 2$, the greater that child's spoken vocabulary would be several years later (Rowe, Özçali;şkan, \& Goldin-Meadow, 2008). Thus the early gestures TD children produce, particularly deictic gestures that identify referents, not only signal the onset of children's first words, but also reliably predict individual variability in children's later spoken vocabulary development.

Compared to early spontaneous gestures, the association between early baby signs (i.e., iconic or arbitrary signs that are deliberately taught by parents) and subsequent spoken vocabulary development in TD children still remains controversial. An early widely-cited training study (Goodwyn et al., 2000) showed that TD infants who were exposed to baby signs systematically from age $0 ; 11$ onward developed better expressive and receptive language skills at 2;0, compared to infants who received either verbal or no training. However, a more recent meta-analysis (Johnston, Durieux-Smith, \& Bloom, 2005) that examined several other studies on baby sign training in TD infants questions the generalizability of the positive results from this earlier work largely due to methodological shortcomings (e.g., lack of adequate control/comparison groups, small sample size; see also Paling, 2007). In fact, a more recent baby sign training study with $0 ; 8$ - to 1;8-year-old infants that addressed most of these methodological issues showed no effect of baby sign 
training on infants' subsequent language development (Kirk, Howlett, Pine, \& Fletcher, 2013). Goodwyn et al. (2000) argue that baby signs might act as a scaffold, helping children transition to the more challenging task of producing words. At the same time, unlike spontaneous gestures, TD children use baby signs for a very short period of time before they produce verbal labels (Acredolo \& Goodwyn, 1988), suggesting a somewhat limited role to baby signs in their subsequent language development. The existing studies on baby signsexcept for one-suggest a lack of positive association between baby sign and spoken vocabulary development in TD children; the methodological issues in some of the studies also highlight the need for additional more tightly controlled experiments to more fully understand the contribution of baby sign to language development. Overall, the overarching evidence from TD children suggests that gesture-specifically deictic gestures, but not baby signs, are positively related to spoken language development.

\section{Role of gesture and baby sign in the spoken vocabulary development of children with DS}

Children with DS show extensive delays in vocabulary development (Beeghly \& Cicchetti, 1987; Miller, 1999), switching often to the manual modality to compensate for the difficulties they encounter in speech production (e.g., Caselli, Vicari, Longobardi, Lami, Pizzoli, \& Stella, 1998; Franco \& Wishart, 1995). In fact, as suggested by earlier work (Broadley, MacDonald, \& Buckley, 1995; Jarrold \& Baddaley, 2001), children with DS show impairments in the phonological loop components of working memory, which feed into the planning and articulation of meaningful sounds (i.e., words). On the other hand, their visual short-term memory is largely non-impaired, particularly when considered relative to their nonverbal mental abilities. As such, the manual modality (gestures, signs) might present itself as a more accessible communicative tool for children with DS compared to spoken modality (words), particularly at the early stages of language development.

Much of the earlier research on the production of gesture by children with DS, using parental checklist measures (MacArthur Communicative Development Inventory; Fenson et al., 1993), showed greater reliance on gesture by young children with DS than TD children comparable in language ability. For example, Italian (Caselli et al., 1998) and American (Singer Harris, Bellugi, Bates, Jones, \& Rossen, 1997) 1;0- to 6;0-year-old children with DS were reported by their parents to express a greater repertoire of meanings in gesture than in speech, compared to TD children. A similar group difference in gesture repertoire was also found in quasi-experimental studies eliciting labels for objects. Three- to 4;0-year-old children with DS, when asked to label referents in pictures, produced greater number of both deictic and iconic gestures in their responses, compared to spoken vocabulary-size-matched TD children (Stefanini et al., 2007; Stefanini, Recchia, \& Caselli, 2008). On the other hand, studies that examined children's spontaneous production of gesture showed no evidence of a group difference in children's gesture repertoires (Iverson, Longobardi, \& Caselli, 2003; Zampini, 2008). An earlier study with five 4;0-year-old children with DS showed that children with DS did not differ from expressive-language matched TD children in their overall rates of gesture production; the two groups were also comparable in their production of different gesture types, including deictic and iconic gestures (Iverson et al., 2003). The existing work thus suggest that children with DS gesture frequently-although studies vary in their definition of what counts as gesture, with some including baby signs and other 
nonverbal behaviors (e.g., action on objects, routinized games; Caselli et al., 1998) in their analysis, while others focus on only spontaneous gestures produced by the child (e.g., Iverson et al., 2003). Most of the earlier work on gesturing in children with DS was also primarily concerned with the amount of gestures children with DS produced, leaving the link between gesture and later spoken vocabulary development relatively unexplored. The only exception to this is the work by Mundy and colleagues (Mundy, Sigman, Kasari, \& Yirmiya, 1989; Mundy, Kasari, Sigman, \& Ruskin, 1995; see also Wetherby, Yonclas \& Bryan, 1989) that showed a relation between early deficits in nonverbal requesting (e.g., extending the hand to request a toy) and later deficits in spoken vocabulary development in children with DS (Mundy et al., 1989).

Even though several researchers argue that sign language training might be particularly beneficial for children with DS, who use baby signs for extended periods due to the difficulties they encounter in speech production (Abrahamsen et al., 1985; Clibbens, 2001), there are very few studies that examined the effects of baby sign use on spoken vocabulary development in children with DS. Of the few existing studies, some show that children with DS can acquire signs with relative ease (e.g., Miller, 1992; Woll \& Grove, 1996), turning them later into spoken words (Kouri, 1989); while a few others suggest a positive impact of sign training on subsequent language development of children with DS (Launonen, 1996). The relatively few studies examining the effects of sign training in children with DS, with the added variability in the data collection procedures-from case studies (e.g., Kouri, 1989) to interventions with small samples (e.g., Launonen, 1996) — make it difficult to draw broader conclusions about the potential effects of baby signs on spoken vocabulary development in children with DS. Nonetheless, the overarching evidence from children with DS—even limited in scope—suggests that baby sign use might be positively related to spoken language development.

Gesture and spoken language development go hand-in-hand in TD children, with gesture predicting the time of acquisition, content and size of children's subsequent spoken vocabularies. Compared to TD children, children with DS show marked deficits in spoken language, but strengths in gesture and baby sign production. In this study we ask whether the process of spoken vocabulary development in children with DS is primarily driven by overall rates of early spontaneous gesture production-specifically deictic gestures that indicate objects—or, alternatively, whether vocabulary development is more closely tied to the production of baby signs that act like words for DS children for an extended period of time at the early stages of language learning.

\section{Methods}

\section{Participants}

All mother-child dyads were participants in a longitudinal study on the development of joint engagement (Adamson, Bakeman, \& Deckner, 2004; Adamson, Bakeman, Deckner, \& Romski, 2009). In this study, we focus on the 23 children with Down syndrome (17 boys; $\mathrm{M}_{\text {age at initial observation }}=2 ; 6 ;$ range $\left.=1 ; 8-3 ; 4\right)$ and 23 TD children ( 18 boys;

$\mathrm{M}_{\text {age at initial observation }}=1 ; 6$; range $\left.=1 ; 6-1 ; 6\right)$; the two groups were drawn from a larger sample of 56 TD children and 29 children with DS with the goal to create two groups similar 
in expressive language for the current study. The two groups of children that form our sample were thus comparable in their productive spoken vocabulary for word tokens $\left(\mathrm{M}_{\mathrm{TD}}=168.26\right.$ [SD=125.18] vs. $\mathrm{M}_{\mathrm{DS}}=145.43$, [SD=88.75]; Kruskal-Wallis, $\left.\mathrm{H}(1)=.21 p=.64\right)$ and were marginally different for word types $\left(\mathrm{M}_{\mathrm{TD}}=28.43\right.$ [SD=26.90] vs. $\mathrm{M}_{\mathrm{DS}}=18.34$, [SD=22.78]; Kruskal-Wallis, $\mathrm{H}(1)=.3 .83 p=.05)$ at the initial observation. Even though children with DS were on average one year older than TD children, the comparability of the two groups on word production (i.e., tokens) was particularly important for our study, because we were interested in group differences in the production of each gesture and sign type that were not driven by differences in speech production. The majority of the children in both groups were Caucasian (TD=74\%, $\mathrm{DS}=83 \%)$, and all children were learning English as their native language. At the time of data collection, the majority of the children in the DS group $(65 \%)$ were receiving speech therapy once or twice a week. The data for the $23 \mathrm{TD}$ children included in this study also served as the comparison sample in an earlier study examining the gesture-speech system in children with ASD (Özçalı;şkan, Adamson, \& Dimitrova, 2015).

\section{Procedure for data collection}

All children were videotaped in a playroom in the laboratory by two cameras placed behind one way-mirrored windows on opposite walls of the playroom, as they interacted with their parents, using the Communication Play Protocol (CPP; Adamson et al., 2004). The CPP is designed to elicit semi-naturalistic observations of parent-child communication using a series of scenes applicable to a diverse group of young children; and each scene involves the caregiver acting out a plot using props. We used 4 five-minute CPP scenes: two that encourage requesting (help getting toys from a high shelf, help playing with complex toys) and two that encourage commenting (discussing pictures, discussing objects in a container), resulting in 20 minutes of observation for each individual child.

\section{Procedure for data coding}

Gestures and baby signs-All video-recorded observations were coded for gesture and for baby signs by trained research assistants. We defined baby sign as an arbitrary or an iconic hand movement that was taught deliberately by an adult, following earlier work (Acredolo \& Goodwyn, 1988, 1996). Baby signs that were arbitrary in form did not have any iconic or indexical relation to the referent that they represented (e.g., tap fingertips of pursed hands together to convey 'more', tap wrists of fisted hands together to convey working), necessitating deliberate instruction by an adult at or prior to our observations. Many of these baby signs were in fact based on signs from American Sign Language (ASL). Baby signs that were iconic in form depicted the characteristic actions or attributes of the referents that they represented. However, different from spontaneous iconic gestures, they were either produced in identical handshape form by both the parent and the child or produced in identical handshape form repeatedly by the child to refer to the same referent within the initial observation session-a similarity of form that is never observed in spontaneous iconic gestures produced by parents and children in early interactions (Özçalı;şkan \& Goldin-Meadow, 2011). The baby signs that were arbitrary in form accounted for the majority of the baby signs in our data (80\%), while the baby signs that were iconic in form were relatively rare (20\%). 
We defined gesture as a symbolic hand or body movement that was produced spontaneously by the child without any direct instruction from the mother (Özçalı;şkan \& Goldin-Meadow, $2005 \mathrm{a}$ ). Actions on objects (e.g., twisting a jar open, offering a toy) were not counted as gestures. The only exception was when the child brought an object to the mother's attention by holding up the object; these show gestures served the same function as the pointing gestures and were coded as deictic gestures. We also further coded gesture into types following McNeill (1992), as either deictic (i.e., indexical gestures that indicate objects/ locations such as pointing at a ball, holding up a bottle), conventional (i.e., gestures that convey culturally prescribed meanings with prescribed gesture forms such as nodding the head to convey affirmation), or iconic (i.e., spontaneous gestures that convey actions or features associated with objects, such as holding cupped hands in air to indicate roundness of a ball).

Language level and outcome-We assessed children's spoken vocabulary at the initial observation (1;6 for TD children, 2;6 for children with DS) for both word tokens and word types using previously transcribed transcripts (Adamson \& Bakeman, 2006). We also computed children's vocabulary size (i.e., the number of words the child produces) one year later, using the standard score on the Expressive Vocabulary Test (EVT; Williams, 1997) as our spoken vocabulary outcome measure.

Statistical analysis-We computed the total number of baby signs and gestures (deictic, conventional, iconic) children produced at initial observation (TD:1;6, DS:2;6). We also assessed children's spoken vocabulary, using EVT, one year later, at 2;6 for TD children and at 3;6 for children with DS. We analyzed differences in gesture, baby sign, and word production with Kruskal-Wallis tests-with group (TD, DS) as a between subjects factorand with Mann-Whitney tests, due to the violation of normality in the distribution of the data. We analyzed the relation between children's early production of baby signs and different gesture types and their later spoken vocabulary size with Spearman's zero-order correlations. A few children (2 TD and 3 with DS) did not complete the vocabulary test (EVT); therefore their scores were not included in the correlational analysis, reducing the sample size to 21 for TD children and 20 for children with DS for the correlational analysis.

Reliability-Intercoder agreement was assessed with a second coder who independently coded randomly selected $15 \%$ of the data in each group. Intercoder agreement scores were $89 \%$ for identifying gestures and baby signs, $90 \%$ for assigning meaning to gestures and baby signs, and $93 \%$ for identifying gesture types.

\section{Results}

\section{Do children with Down syndrome differ from TD children in their production of spontaneous gesture and baby signs?}

Beginning with baby signs, we found differences between the two groups. Children with DS produced significantly more baby signs than TD children $\left(M_{\mathrm{DS}}=5.0[\mathrm{SD}=7.22] \mathrm{vs} . M_{\mathrm{TD}}=\right.$ 0.0 [SD=0]; Kruskal-Wallis, $\mathrm{H}(1)=18.88 p<.001)$. In fact, none of the TD children in our sample produced baby signs, whereas $61 \%(14 / 23)$ of the children with DS produced at least 
one baby sign in the initial observation. The baby signs primarily conveyed action (36\%; e.g., form fists with both hands and tap wrists together to convey 'working') or object information (22\%; place and twist hook-shaped finger above cheek to convey 'apple'), along with several signs that marked social requests and responses (42\%, e.g., tap pursed hands at fingertips to convey 'more', rub chest with palm in circular motion to convey 'please', move fist forward and rock back and forth to convey 'yes'; see Appendix 1 for a list of all baby signs children with DS produced).

Turning next to gesture, we also found differences between the two groups, but in the opposite direction. Children with DS produced significantly fewer gestures than TD children $\left(M_{\mathrm{DS}}=26.91\right.$ [SD=22.44], range=6-83 vs. $M_{\mathrm{TD}}=46.78$ [SD=25.03], range=10-116; Kruskal-Wallis, $\mathrm{H}(1)=7.98, p=.005)$. At the same time, the two groups of children used the same three gesture types (deictic, conventional, iconic). However, when we examined overall production rates for each gesture type, we once again observed group differences. As can be seen in Fig. 1, compared to TD children, children with DS produced significantly fewer deictic $\left(\mathrm{M}_{\mathrm{DS}}=14.35\right.$ [SD=15.93] vs. $\mathrm{M}_{\mathrm{TD}}=27.96$ [SD=23.96]; Kruskal-Wallis, $\mathrm{H}(1)=5.38, p=.02)$ and conventional gestures $\left(\mathrm{M}_{\mathrm{DS}}=12.47[\mathrm{SD}=10.69]\right.$ vs. $\mathrm{M}_{\mathrm{TD}}=18.70$ [SD=9.92]; Kruskal-Wallis, $\mathrm{H}(1)=4.99, p=.03)$. Children rarely used spontaneous iconic gestures, which accounted for less than one percent of gesture production in both groups $\left(\mathrm{M}_{\mathrm{DS}}=0.09\right.$ [SD=0.29] vs. $\mathrm{M}_{\mathrm{TD}}=0.13$ [SD=0.34]; Kruskal-Wallis, $\left.\mathrm{H}(1)=.22, p=0.64\right)$.

\section{Does the individual variability in the production of gestures and/or baby signs predict the size of children's spoken vocabulary one year later?}

Compared to TD children, children with DS showed significant deficits in their production of both deictic and conventional gestures, but a significant advantage in their production of baby signs. Next we asked whether the differences that we observed in the production of each gesture type and in baby signs was related to children's spoken vocabulary, assessed one year later. In earlier work (Özçalı;skan et al., 2015), we found that the production of deictic but not other gesture types reliably predicted expressive vocabulary size one year later for TD children $(\mathrm{N}=21, r h o=.64, p=.002)$, using the same sample of TD children. In this study, we asked whether the same predictive relation between early deictic gesture and later spoken vocabulary holds for children with DS, and if not, whether baby signs might be a better predictor of later vocabulary in this group. We found that it was the production of baby signs that predicted expressive vocabulary size one year later for children with DS $\left(\mathrm{N}=20\right.$, Spearman's rho $=.60, p=.005$; see Fig. 2A). ${ }^{2}$ Neither deictic nor conventional gestures produced by children with DS had a significant relation to later spoken vocabulary ( $r h o=-.14, p=.56$ for deictic, and $r h o=0.09, p=.71$ for conventional, Fig. 2B).

\section{Discussion}

In this study, we asked how children with DS compare to TD children in the amount and types of spontaneous gestures and baby signs that they produce at the beginning stage of language learning and whether the deficits that are commonly observed in the spoken

\footnotetext{
${ }^{2}$ The positive correlation between early baby sign and later expressive vocabulary remains significant not only for baby sign tokens $(\mathrm{N}=20$, rho=.60, $p=.005)$, but also for baby sign types $(\mathrm{N}=20, r h o=.54, p=.01)$.
} 
vocabulary development of children with DS are best predicted by their gesture or sign production. We found that children with DS showed significant deficits in their spontaneous gesture production, particularly for deictic gestures, but strengths in their production of baby signs, compared to TD children similar in language ability. Importantly, the production of baby signs predicted the spoken vocabulary size of children with DS one year later, but no such predictive association was found for either deictic or conventional gestures and later spoken vocabulary size.

Earlier work suggested that children with DS compensate for the difficulties they encounter in speech, relying on nonverbal behaviors, such as gestures and signs, at rates comparable to (Iverson et al., 2003, Zampini \& D'Odorico, 2011), or, in some cases, even higher than TD children (Caselli et al., 1998. Franco \& Wishart, 1995; Singer Harris et al., 1997; Stefanini et al., 2007). Children with DS in our study diverged from this pattern, producing significantly fewer gestures than TD children. What explains these differences? Unlike earlier work, most of which relied on very small sample sizes and more indirect, broadlydefined measure of child gesture production (i.e., parental checklist), the current study with its relatively larger sample size, semi-naturalistic observations, and more precise definition of gesture might be more likely to capture individual variability evident in children's gesture use, and accordingly, provide a more representative distribution of actual gesture production by children with DS. In fact, one of the key contributions of this work is that children with DS gestured less than TD children even if they were comparable in the amount of speech that they produced, suggesting that speech was not the driving force behind differences in rates of gesture production in the two groups.

Importantly, the two groups of children showed different areas of strength in their use of early nonverbal symbols: children with TD showed relative strengths in deictic gesture production, indicating a large repertoire of objects by pointing at them, but did not produce any baby signs. Children with DS, on the other hand, showed marked deficits in deictic gesture production, but used a large repertoire of baby signs, conveying a broad range of meanings. Perhaps, not surprisingly, it was the deictic gestures that predicted the extent of TD children's vocabularies, while baby signs were positively related to later vocabulary of children with DS. But why do deictic gestures or baby signs serve as strong predictors of later spoken vocabulary selectively in the two groups? Deictic gesture is strongly tied to the immediate communicative context shared by the parent and the child and serves as a key ingredient in building joint attention between parent and child around objects. TD children initially indicate objects in gesture, simply by pointing at them; and parents rely on the deictic gestures that their children produce, often times translating these gestures into words. And not surprisingly, children are more likely to produce the word for the object that they initially conveyed in gesture if their mothers provided a label for their gesture indicating that object (Goldin-Meadow, Goodrich, Sauer, \& Iverson, 2007). Thus, parental translations of early deictic gestures might be the process that explains the close association between deictic gestures and later spoken vocabulary in typical development. Similarly, baby signs are learned in the immediate everyday context of repeated one-to-one communication with the parent; each time a parent wants to communicate about a particular object, she produces the same sign for it—creating a highly-scaffolded interactive routine centered around referent-symbol mappings. These repeated exposures to signed symbols, in turn, might 
create a state of "symbol mindedness" (DeLoache, 2004) in children with DS—namely the idea that symbols stand for objects-eventually helping them to move from a repertoire of signed symbols to a repertoire of words as they gain better control of their speech production. In fact, previous work suggests that children with DS do not differ from TD children in their ability to build joint attention with their communicative partners (Adamson et al., 2009), but they show greater sustained interest in people than in objects, compared to TD children (Adamson, Deckner, \& Bakeman, 2010). As such, baby signs, that involve repeated interpersonal exchanges about particular objects or actions (e.g., tapping thigh to convey dog, twisting thumb and index fingers on both cheeks to convey laughing) between child and caregiver might be particularly salient in identifying mappings between referents and symbols for children with DS, playing a more prominent role in their spoken vocabulary development. In fact, unlike parents of TD children who never used baby signs with their children, the majority (78\%) of the parents of children with DS in our sample produced baby signs when interacting with their children, thus providing models for their children to refer to different objects with baby signs. In addition, unlike TD children who on average produce the verbal label for a particular referent three months after they have expressed it in gesture (Iverson \& Goldin-Meadow, 2005), children with DS rely on baby signs for a more extended period of time, most likely as a way to fill in lexical gaps in their spoken language vocabularies. In fact, children with DS who did produce baby signs in our study also had larger repertoire of spoken words at their disposal than the ones who did not produce any baby signs in the initial observation session ( $M=24.21$ [27.55] vs. $M=9.2$ [6.28], $H(1)=6.22$, $p=.01$ ). Moreover, when we estimated children's vocabulary size (i.e., number of different referents conveyed) using both speech and baby signs in the initial observation, the extent of children's vocabulary became comparable in the two groups $\left(\mathrm{M}_{\mathrm{DS}}=20.52\right.$ [SD=23.71] vs. $\mathrm{M}_{\mathrm{TD}}=28.43$ [SD=26.90], $H(1)=2.01, p=0.16$ ), further suggesting a role to baby signs akin to spoken words in early communicative repertoires of children with DS.

One question that remains is whether there is a causal link between early gesture and/or baby sign and later spoken vocabulary development in both TD children and children with DS, or alternatively, some kind of third variable can explain changes in both gesture/baby sign and later speech production. That is, perhaps children who are good at learning baby signs or gestures are also (relatively) good at learning words, because both tasks use some of the same underlying skills. Given the observational nature of our data, we cannot attribute a causal role to gesture or baby sign in fostering children's vocabulary development. But our findings are suggestive and highlight the need for future work that manipulates children's early nonverbal behaviors and explores the effect this manipulation might have on the subsequent spoken vocabularies children with DS develop.

Another question that remains is whether children with DS who do and who do not use baby signs are equally likely to use gestures; and if so whether gesture assumes a similar role in language learning in the two groups as children develop increasingly complex language abilities. Interestingly, some of the children with DS in our study did not use any baby signs in our initial observation, but they nonetheless produced gestures $\left(\mathrm{N}=9, \mathrm{M}_{\text {gesture }}=28.33\right.$ [SD=23.52]) and at frequencies comparable to children who used baby signs $(\mathrm{N}=14$, $\mathrm{M}_{\text {gesture }}=26.00$ [SD=22.57], Mann-Whitney U (1) 62.5, $p=.98$ ). The two groups (i.e., children who did use vs. those who did not use baby signs) were also comparable in the 
types of gestures that they produced, for both deictic ( $\mathrm{M}=12.64$ [14.41] vs. $\mathrm{M}=17.0$ [18.63]), $\mathrm{U}(1)=54, p=.60)$, conventional $(\mathrm{M}=13.21$ [10.08]) vs. $\mathrm{M}=11.33$ [12.12], $\mathrm{U}(1)=52.5, p=.52)$, and iconic ( $\mathrm{M}=.14[.36])$ vs. $\mathrm{M}=0[0], \mathrm{U}(1)=54, p=.60)$ gestures, suggesting that neither the amount nor the nature of the gestures children with DS produced was affected by their tendency to use or not to use baby signs. There is also recent work that suggests that children with DS who do and who do not produce baby signs are as likely as TD children to convey unique information in gesture not found in speech at the early stages of language acquisition (Dimitrova, Özçalı;şkan, Adamson, 2015), and later on to combine these gestures with words to form gesture-speech combinations before producing two-word speech (Iverson et al., 2003). These findings, even limited in scope, nonetheless suggest that signing might have little bearing on the development of a gesture system.

In summary, our study showed distinct roles gestures and baby signs play in the language acquisition of TD children and children with DS—-with a positive relation between deictic gestures and subsequent spoken vocabulary in TD children and baby signs and later spoken vocabulary in children with DS. Our results further highlight the important role nonverbal communication plays in the spoken language development of children with developmental disorders.

\section{Acknowledgments}

This research was supported by grants from NSF (BCS 1251337), NIH (R01 HD035612), and Swiss NSF (PBLAP1_142782).

\section{References}

Abrahamsen A, Cavallo MM, McCluer JA. Is the sign advantage a robust phenomenon? From gesture to language in two modalities. Merrill-Palmer Quarterly. 1985; 31:177-209.

Acredolo LP, Goodwyn SW. Symbolic gesturing in in normal infants. Child Development. 1988; 59:450-466. [PubMed: 2452052]

Acredolo, LP.; Goodwyn, SW. Baby Signs. Chicago, IL: Contemporary Books; 1996.

Adamson LB, Bakeman R. The development of displaced speech in early mother-child conversations. Child Development. 2006; 77:186-200. [PubMed: 16460533]

Adamson LB, Bakeman R, Deckner DF. The development of symbol-infused joint engagement. Child Development. 2004; 75:1171-1187. [PubMed: 15260871]

Adamson LB, Bakeman R, Deckner DF, Romski MA. Joint engagement and the emergence of language in children with autism and Down syndrome. Journal of Autism and Developmental Disorders. 2009; 39:84-96. [PubMed: 18581223]

Adamson LB, Deckner DF, Bakeman R. Early interests and joint engagement in typical development, autism and Down Syndrome. Journal of Autism and Other Developmental Disorders. 2010; 40:665676.

Bates, E.; Benigni, L.; Bretherton, I.; Camaioni, L.; Volterra, V. The Emergence of Symbols: Cognition and Communication in Infancy. New York: Academic Press; 1979.

Beeghly, M.; Cicchetti, D. An organizational approach to symbolic development in children with Down syndrome. In: Cicchetti, D.; Beeghly, M., editors. Atypical Symbolic Development. San Francisco: Jossey-Bass; 1987. p. 5-30.

Broadley I, MacDonald J, Buckley SJ. Working memory in children with Down syndrome. Down Syndrome Research and Practice. 1995; 3(1):3-8. 
Caselli MC, Vicari S, Longobardi E, Lami L, Pizzoli C, Stella G. Gestures and words in early development of children with Down syndrome. Journal of Speech, Language and Hearing Research. 1998; 41:1125-1135.

Clibbens J. Signing and lexical development in children with Down Syndrome. Down Syndrome Research and Practice. 2001; 7:101-105.

DeLoache JS. Becoming symbol-minded. Trends in Cognitive Sciences. 2004; 8(2):66-70. [PubMed: 15588810]

Dimitrova N, Özçalı;şkan S, Adamson LB. Parents' translations of child gesture facilitate word learning in children with autism, Down syndrome and typical development. 2015 Manuscript under review.

Fenson, L.; Dale, P.; Reznick, JS.; Thal, D.; Bates, E.; Hartung, JP., et al. The MacArthur Communicative Development Inventories: Users' Guide and Technical Manual. San Diego, California: Singular Press; 1993.

Franco F, Wishart J. Use of pointing and other gestures by young children with Down syndrome. American Journal on Mental Retardation. 1995; 100:160-182. [PubMed: 8527112]

Goldin-Meadow S, Goodrich W, Sauer E, Iverson J. Young children use their hands to tell their mothers what to say. Developmental Science. 2007; 10(6):778-785. [PubMed: 17973795]

Goodwyn S, Acredolo L, Brown C. Impact of symbolic gesturing on early language development. Journal of Nonverbal Behavior. 2000; 24:81-103.

Iverson JM, Capirci O, Caselli MC. From communication to language in two modalities. Cognitive Development. 1994; 9:23-43.

Iverson JM, Capirci O, Longobardi E, Caselli MC. Gesturing in mother-child interactions. Cognitive Development. 1999; 14:57-75.

Iverson JM, Goldin-Meadow S. Gesture paves the way for language development. Psychological Science. 2005; 16(5):367-37. [PubMed: 15869695]

Iverson JM, Longobardi E, Caselli MC. Relationship between gestures and words in children with Down's syndrome and typically developing children in the early stages of communicative development. International Journal of Language \& Communication Disorders. 2003; 38:179-197. [PubMed: 12745936]

Jarrold C, Baddeley A. Short-term memory in Down syndrome: Applying the working memory model. Down Syndrome Research and Practice. 2001; 7(1):17-24.

Johnston J, Durieux-Smith A, Bloom K. Teaching gestural signs to infants to advance child development: A review of the evidence. First Language. 2005; 25:235-251.

Kirk E, Howlett N, Pine KJ, Fletcher B. To sign or not to sign? The impact of encouraging infants to gesture on infant language and maternal mind-mindedness. Child Development. 2013; 84(2):574590. [PubMed: 23033858]

Kouri T. How manual sign acquisition relates to the development of spoken language: A case study. Language, Speech, and Hearing Services in Schools. 1989; 20:50-62.

Launonen, K. Enhancing communication skills of children with Down syndrome: Early use of manual signs. In: von Tetzchner, S.; Jensen, MH., editors. Augmentative and Alternative Communication: European Perspectives. London: Whurr; 1996. p. 213-231.

McNeill, D. Hand and Mind: What Gestures Reveal About Thought. Chicago: The University of Chicago Press; 1992.

Miller, JF. Development of speech and language in children with Down syndrome. In: Lott, IT;; McLoy, EE., editors. Clinical Care for Persons with Down Syndrome. New York: Academic Press; 1992. p. 39-50.

Miller, JF. Profiles of language development in children with Down syndrome. In: Miller, J.; Leddy, M.; Leavitt, L., editors. Improving the Communication of People with Down Syndrome. Baltimore; Brookes: 1999. p. 11-40.

Mundy P, Kasari C, Sigman M, Ruskin E. Nonverbal communication and early language acquisition in children with Down syndrome and in normally developing children. Journal of Speech and Hearing Research. 1995; 38:157-167. [PubMed: 7537345]

Mundy P, Sigman M, Kasari C, Yirmiya N. Nonverbal communication skills in Down syndrome children. Child Development. 1989; 59:235-249. [PubMed: 2963734] 
Özçalı;şkan Ş, Adamson LB, Dimitrova N. Early deictic but not other gestures predict later vocabulary in both typical development and autism. 2015 Manuscript under review.

Özçalı;şkan Ş, Goldin-Meadow S. Do parents lead their children by the hand? Journal of Child Language. 2005a; 32(3):481-505. [PubMed: 16220632]

Özçalı;şkan Ş, Goldin-Meadow S. Gesture is at the cutting edge of early language development. Cognition. 2005b; 96(3):B101-B113. [PubMed: 15996556]

Özçalı;şkan, Ş.; Goldin-Meadow, S. Is there an iconic gesture spurt at 26 months?. In: Stam, G.; Ishino, M., editors. Integrating Gestures: The Interdisciplinary Nature of Gesture. Amsterdam: John Benjamins; 2011. p. 163-174.

Paling J. Critical review: Does baby sign language have a positive affect on language development of typically developing, hearing infants of hearing parents? 2007 Unpublished manuscript.

Rowe M, Özçalı;skan S, Goldin-Meadow S. Learning words by hand: Gesture's role in predicting vocabulary development. First Language. 2008; 28(2):182-199. [PubMed: 19763249]

Singer Harris N, Bellugi U, Bates E, Jones W, Rossen M. Contrasting profiles of language development in children with Williams and Down Syndromes. Developmental Neuropsychology. 1997; 13:345-370.

Stefanini S, Caselli MC, Volterra V. Spoken and gestural production in a naming task by young children with Down syndrome. Brain and Language. 2007; 101(3):208-221. [PubMed: 17379294]

Stefanini S, Recchia M, Caselli MC. The relationship between spontaneous gesture production and spoken lexical ability in children with Down syndrome in a naming task. Gesture. 2008; 8(2):197218.

Tager-Flusberg, H. Atypical language development: Autism and other neurodevelopmental disorders. In: Hoff, E.; Shatz, M., editors. Blackwell Handbook of Language Development. Blackwell Publishers; 2007.

Tager-Flusberg H, Calkins S, Noin I, Baumberger T, Anderson M, Chadwick-Denis A. A longitudinal study of language acquisition in autistic and Down Syndrome children. Journal of Autism and Developmental Disorders. 1990; 20:1-22. [PubMed: 2139024]

Walker, M. Teaching Sign Language to Deaf Mentally Handicapped Adults (A Practical Account and an Experimental Evaluation). Language and the Mentally Handicapped; IMS Conference Proceedings; Kidderminster: British Institute of Mental Handicap; 1977. p. 3-25.

Wetherby AM, Yonclas DG, Bryan AA. Communicative profiles of preschool children with handicaps: Implications for early identification. Journal of Speech and HearingDisorders. 1989; 54:148-158.

Williams, KT. Expressive Vocabulary Test. 1. Circle Pines, MN: American Guidance Service; 1997. EVT

Woll B, Grove N. On language deficits and modality in children with Down syndrome: A case study. Journal of Deaf Studies and Deaf Education. 1996; 1:271-278. [PubMed: 15579830]

Zampini L. Produzione gestuale e pre-verbale a 24 mesi in bambini con sindrome di Down e bambini parlatori tardivi [Gestural and pre-verbal communication in 24-month-old children with Down syndrome and late-talking children]. Psicologia Clinica Dello Sviluppo. 2008; 3:511-527.

Zampini L, D’Odorico L. Gesture production and language development. A longitudinal study of children with Down syndrome. Gesture. 2011; 11(2):174-193.

\section{Appendix I}

\begin{tabular}{|l|l|}
\hline BABY SIGN & SIGN DESCRIPTION \\
\hline Signs for objects & \\
\hline Apple & Hook index finger and twist at cheek \\
\hline Ball & Using both hands, tap fingertips together outlining the shape of a ball \\
\hline Bear & Cross arms with claw hands and scratch shoulders \\
\hline Boy & Tap four fingers and thumb together as if grasping bill of a baseball cap \\
\hline
\end{tabular}




\begin{tabular}{|c|c|}
\hline BABY SIGN & SIGN DESCRIPTION \\
\hline Cat & Using the index finger and thumb of one hand, tap together and pull as if stroking a cat's whiskers \\
\hline Dog & Use palm to tap thigh \\
\hline Duck & Using two fingers and thumb facing forward, open and close near mouth \\
\hline Fish & $\begin{array}{l}\text { Extend hand with fingers facing forward and thumb pointing up and shake hand in a back and } \\
\text { forth motion }\end{array}$ \\
\hline Hat & Using palm, tap head \\
\hline Nose & Tap index finger to nose \\
\hline Turtle & Make a fist with thumb forward, place palm of other hand on top and wiggle thumb \\
\hline Water & Make a "W" with hand and tap mouth \\
\hline \multicolumn{2}{|c|}{ Signs for actions } \\
\hline All done & Palms facing in and rotate hands to make palms face outward \\
\hline Eat & Tap on mouth with pursed tips of the fingers \\
\hline Go & Move both hands with outstretched index fingers forward \\
\hline Help & Place one fist with thumb up on palm of other hand and move both up \\
\hline Laugh & Twist outward joined thumb and index finger of each hand on both cheeks \\
\hline Listen & Place palm behind ear \\
\hline Open & Place palms together as if opening and closing a book \\
\hline Play & Using thumb and pinkie on both hands with other fingers folded, twist back and forth \\
\hline Stop & Place forward facing hand on flat palm in a chopping motion \\
\hline Work & Make two fists, and tap wrists together \\
\hline \multicolumn{2}{|l|}{ Other signs } \\
\hline Happy & Using both hands, sweep upwards on chest \\
\hline Pretty & Using palm, sweep across face \\
\hline Red & Using index finger, swipe bottom lip downward \\
\hline Yes & Make a forward facing fist and rock wrist back and forth \\
\hline More & Tap hands together using the tip of the thumb and tips of the fingers \\
\hline Please & Using palm, rub on chest in a circular motion \\
\hline
\end{tabular}




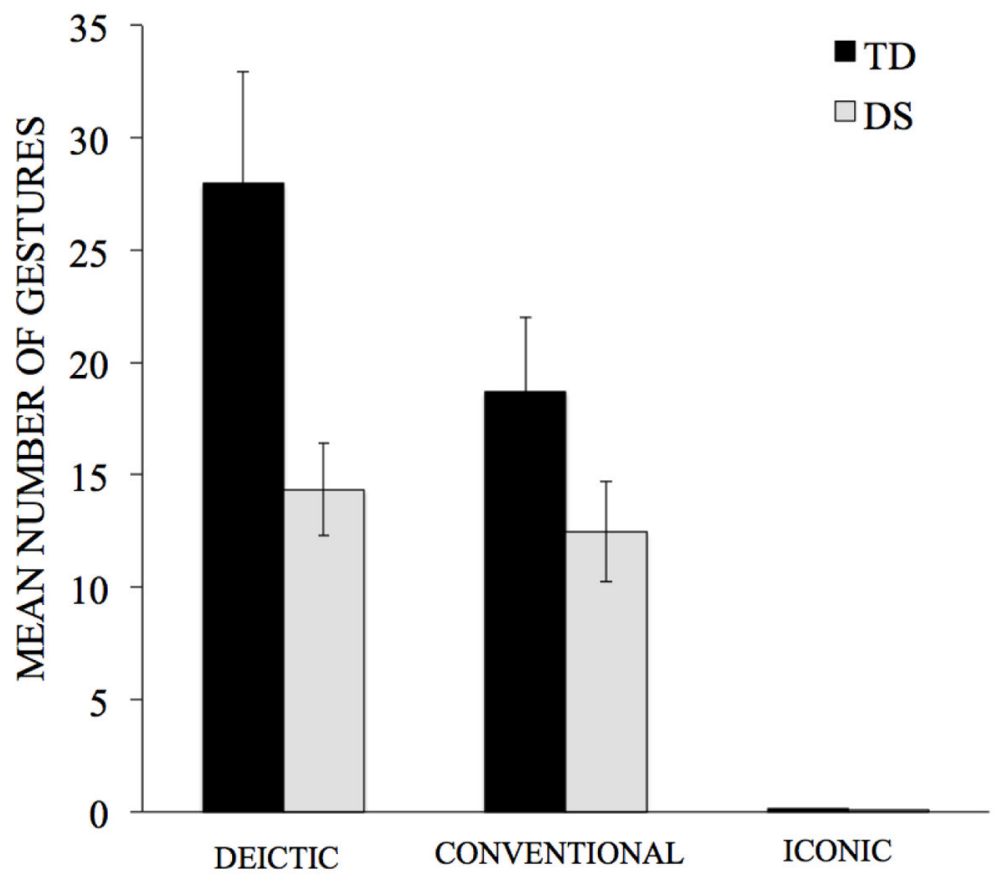

Figure 1.

Mean number of deictic, conventional and iconic gestures produced by TD children (dark columns) and children with DS (light columns); bars represent standard errors. Majority of the deictic gestures were points both for TD children (95\%) and children with DS (87\%). 
2A. BABY SIGNS

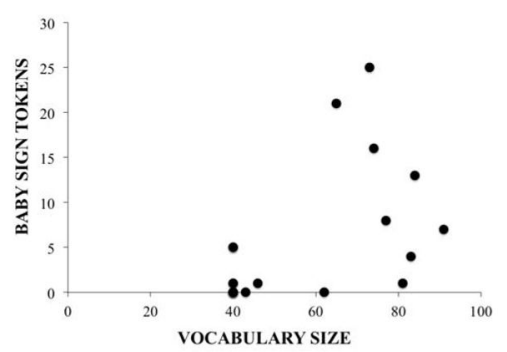

2B. DEICTIC GESTURES

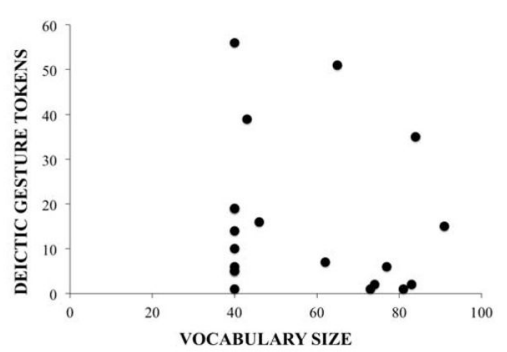

Figure 2.

Distribution of baby signs (left panel) and deictic gestures (right panel) produced by children with DS in relation to their vocabulary size one year later (production rate was much lower for baby signs compared to gestures as captured here by the different y-axis scales in Figures $2 \mathrm{~A}$ and $2 \mathrm{~B}$; only data from 20 children with DS are presented here because 3 of the children did not complete the vocabulary test). 